\title{
Experimental Study on Biochemical Markers of Mandibular Bone Tissue Metabolism in Rats following the Implantation of PAW-1 and Geistlich Bio-0SS Collagen
}

\author{
VIORICA CHETRUS ${ }^{1}$, DUMITRU SARBU ${ }^{1}$, CORNELIU GOREA ${ }^{1}$, IULIAN CHETRUS ${ }^{2 *}$ \\ ${ }^{1}$ Nicolae Testemitanu SUMPh, Republic of Moldova \\ ${ }^{2}$ Grigore T.Popa University of Medicine and Pharmacy, Faculty of Dental Medicine, 16 Universitatii Str., 700115, Iasi, Romania
}

\begin{abstract}
The study is based on the analysis of experimental results and determination of the bone metabolism markers by histochemical and biochemical methods performed on animals. The animals were implanted biovitroceramics PAW-1 in the mandible in the form of spongy matrix composed of fluorhydroxyapatite and microcrystallized wollastonite in a glass matrix, elaborated by the company PONETI (Romania) and Geistlich Bio-Oss-Collagen in the form of block (a mixture of granules, $0.25-1 \mathrm{~mm}$ in size) and $10 \%$ fibers of porcine collagen. Geistlich Bio-Oss Collagen is a natural mineral bone of bovine origin, comparable both chemically and structurally to the mineralized human bone. It has a spongy consistency that allows simple modeling, and collagen facilitates the adaptation of the material on the defect site.The biochemical blood analysis showed an increased activity of bone thermolabile alkaline phosphatase over 30 days, the maximum being reached over 60 days $+20 \%(p<0.05)$ from the beginning of the experiment. The activity of tartrate-resistant bone acid phosphatase, on the contrary, decreased veridically by $22 \%$ over 60 days after implantation. Over 30 days after the beginning of the experiment under the action of the implanted material, the level of average molecules (AM) increased by 35\% ( $p<0.05)$, while nucleotide substances (NS) increased by $51 \%(p<0.05)$. Within 60 days after implantation, the values of these indices showed a decreasing tendency. The fact mentioned above denotes that their osteoregenerative action increases under the influence of implanted materials.
\end{abstract}

Keywords: Thermolabile alkaline phosphatase, tartrate-resistant acid phosphatase, average molecules, nucleotide substances.

Chronic periodontitis (CP) is one of the most common inflammatory diseases of the periodontal tissue, being accompanied by the breakdown of dental-gingival connection and progressive destruction of alveolar processes of the jaws.

Periodontal disease (PD) is not only a dental issue but also a general and even social medical problem, given that it is spread worldwide and the number of teeth extracted due to this condition is much higher than those lost due to dental caries complications [13]. The functional disorders of the stomatognathic system, conditioned by edentiation following PD, develop 5 times more frequently than due to dental caries complications. Bone reshaping comprises 2 processes strictly agreed and correlated, namely: resorption and osteogenesis. The disorders of this balance especially in the resorption process, first cause osteoporosis, then osteolysis $[4,7]$.

Currently, the treatment of periodontitis entails complex measures for the suppression of multiple causes, which are considered as causative factors of chronic periodontitis (CP) evolution.

Scientists concerned with these issues consider that microorganisms are the determining factors [9], therefore antiseptics and antimicrobials are used as a remedy of treatment. This treatment is effective in the early stages. The treatment of the advanced forms of PD is much more complicated, such as CP with the formation of periodontal pockets (PP) and damage to the alveolar apophysis bone. In these cases the treatment requires radical and costly measures to suppress the destructive-inflammatory process in the periodontium and to restore the bone tissue of the alveolar apophysis lost following lysis.
In recent years, periodontal surgery has expanded its scope due to the possibilities of selecting materials that stimulate the periodontal tissue regeneration. It has been established that in chronic marginal periodontitis, the affected foci can be eliminated by surgical means in shorter time, ensuring lasting remissions as well. The conservative therapy, widely used nowadays, requires a large number of visits to the dentist [1].

In addition, by administering antibiotics, the development of microbial flora in the periodontal pockets is inhibited for a relatively short period of time, therefore surgery is considered one of the mostimportant therapeutic strategies in periodontitis. Being preceded by antiinflammatory therapy, it will lead to the stimulation and reparative regeneration of the affected tissues for a long time [5].

With the advent of the materials that stimulate osteogenesis and their implantation in the surgical treatment of periodontitis, there are reports confirming partial restoration of the alveolar apophysis bone of the periodontium and dento-gingival junction [1-3,10,11]. Currently, hydroxyapatite and collagen-based matrices have proven to be among the most suitable for dentalperiodontal surgery. Physically and chemically the matrix can be compared to the mineralized matrix of the human bone. It is easy to apply in the bone defect. They are not toxic and irritating, and do not cause anyallergic reactions. They are sterile and hemostatic, providing protection of the lesion, being a reliable surgical dressing. By the mode of application, it is comfortable for the dentist. Unlike the gel and granules, the matrix can be fixed very well and does not remove from the injury. As a guided tissue 
regeneration product, it requires a single application in periodontal surgery, reducing pain and ensuring the alveolar bone appearance accompanied by the restoration of epithelial insertion.

Objectives of the study: to carry out an experimental study of the integration of PAW1 and Geistlich Bio-Oss Collagen replacement materials in the limited tissues, to stimulate the neo-osteogenesis process and the dynamics of accumulation of some markers of bone tissue metabolism in the tissues and blood.

The idea of the study was generated by the previous research carried out by some authors [11, 13].

\section{Experimental part}

Material and methods

A sample of 12 mature rats weighing 160-180gr were used in the study. Under conditions of aseptic surgery, the animals were anesthetized with $0.6 \mathrm{~mL}$ of calipsol solution per 200gr of body mass and general anesthesia. In compliance with the rules of asepsis and antisepsis, the mucoperiostal flap was detached off the rat's jaw. In the decortified mandible area, 2 bone defects were made with spherical bur No.1. In one of the defects, PAW-1 was implanted as a matrix (fig.1), while in the second defect

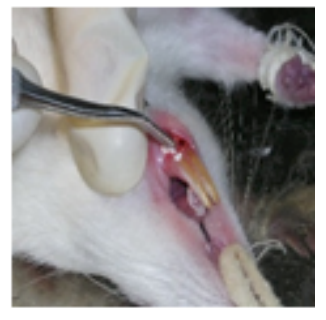

Fig.no.1

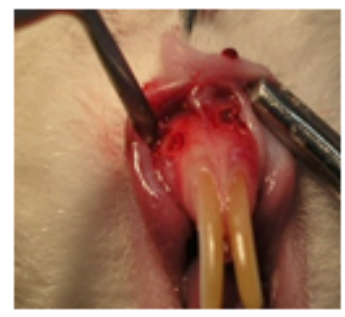

Fig.no.2

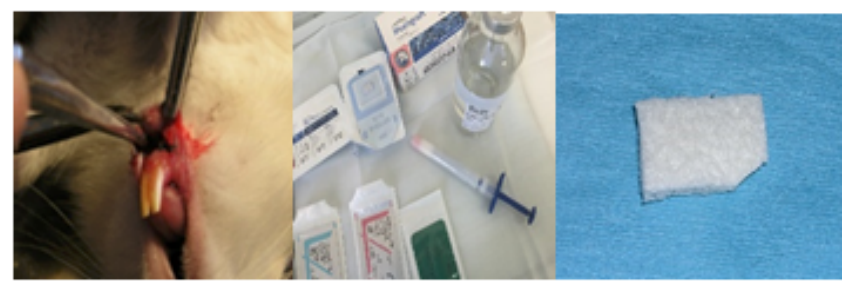

Fig.no.3 Bio-Oss Collagen
Geistlich Bio-Oss Collagen was implanted in the form of block (fig.2). The mucoperiosteal flap was moved towards the crown and was sutured with resorbable thread (fig.3).

The animals were fed three times a day with fruits and vegetables (apples, carrots, beetroot) ground by blender. Vitamins C, D and K were dissolved in the drinking water for osteocalcin synthesis [8]. All the animals survived. At different time periods (14, 30 and 60 days) the animals were sacrificed. Animals blood samples were taken for biochemical tests. After being sacrificed, the mandible was separated from the soft tissues and was macroscopically examined. There were prepared pieces for histological and histochemical examination. Histochemically, osteogenesis markers have been studied with a very important role in the bone tissue metabolism such as alkaline and acid phosphatase, 5-nucleotidase, osteocalcin and non-specific esterase.

Enzymological investigations of the osteogenesis process consist in revealing the main markers that populate the area of surgical intervention in periodontal tissues.

It is known that alkaline phosphatase, 5-nucleotidase and osteocalcin are markers of osteoblasts, and acid phosphatase is the marker of osteoclasts.

To evaluate the action of PAW 1 and Geistlich Bio-Oss Collagen on animals, the dynamics of some specially selected biochemical indices has also been studied, namely:

-The activity of bone thermolabile alkaline phosphatase, bone-tartrate-resistant acid phosphatase.

-The level of bone tissue metabolism markers, level of average molecules, necrotic substances, nitric oxide in rats blood serum 14, 30 and 60 days after the implantation of PAW-1 and Geistlich Bio-Oss Collagen biomaterials [6].

\section{Results and discussions}

The activity of alkaline phosphatase 14 days after the implantation of biomaterials PAW-1 matrix and Geistlich Bio-Oss Collagen is increased in numerous cells in the granulation tissue, formed in the defect area and on the surface of the bone tissue bundles in the endosteum cells and hematogenous marrow in the mandibular bone cavities.

Table 1

DYNAMICSOF BIOCHEMICAL MARKERS OF BONE TISSUE METABOLISM, LEVEL OF AVERAGE MOLECULES, NUCLEOTIDE SUBSTANCES, NITRIC OXIDE IN BLOOD SERUM IN LABORATORY ANIMALS WITH PAWI AND BIO-OSSBIOVITROCERAMIC IMPLANTS

\begin{tabular}{|c|c|c|c|c|c|c|c|}
\hline $\begin{array}{l}\text { Research } \\
\text { conditions }\end{array}$ & $\begin{array}{l}\text { No. of ani- } \\
\text { ma- ls }\end{array}$ & \begin{tabular}{|l} 
Thermolabil \\
alkaline \\
phosphatase \\
(nmol's/l)
\end{tabular} & $\begin{array}{l}\text { Tartrate-resistant } \\
\text { acid phosphatase } \\
(\mathrm{nmol} / \mathrm{s} \text { ) }\end{array}$ & Coefficient $\mathrm{K}$ & $\begin{array}{l}\text { Average } \\
\text { molecules } \\
\text { (conv. un.) }\end{array}$ & NS (conv. un.) & $\begin{array}{l}\text { Nitric oxide } \\
(\mathrm{mkm} / \mathrm{l})\end{array}$ \\
\hline After 14 days & 4 & $214.0+18.11$ & $2.76+0.19$ & $77.8-8.5$ & $0.386+C .031$ & $2.71+0.031$ & $1.54+0.12$ \\
\hline After 30 days & 4 & $\begin{array}{l}237.4+25.3 \\
(110 \%)\end{array}$ & $3.2+0.29(1 \mathrm{C} \% \%)$ & $74.2-8.7(95 \%)$ & $\begin{array}{l}0.522+0.05^{*} \\
(135 \%)\end{array}$ & $\begin{array}{l}3.67+0.4^{*} \\
(135 \%)\end{array}$ & $\begin{array}{l}2.6+0.27^{*} \\
(151 \%)\end{array}$ \\
\hline After 60 days & 4 & $\begin{array}{l}258.2+25.6 \\
(120 \%)\end{array}$ & $2.15+0.2^{*}(78 \%)$ & $\begin{array}{l}120.1+10.2^{*} \\
(154 \%)\end{array}$ & $\begin{array}{l}0.499+0.053 \\
(129 \%)\end{array}$ & $\begin{array}{l}3.05+0.17 \\
(113 \%)\end{array}$ & $\begin{array}{l}2.18+0.34 \\
(128 \%)\end{array}$ \\
\hline
\end{tabular}

The veracity compared to the initial values: * $P<0.05$; Note: Coefficient $K$ - the ratio between thermolabile alkaline phosphatase and

tartrate-resistant acid phosphatase. NS - nucleotide substances 
Besides the process of osteogenesis induction, an increased activity of acid phosphatase in macrophages and associated osteoclasts was also observed.

Increased alkaline phosphatase denotes a process of active differentiation of cells that populate the implantation area of the replacement material.

Over 30 days the activity of alkaline phosphatase is much lower than in the previous stage.The tissue in the formed defect region contains numerous osteocytes, while the number of osteoblasts-processors of alkaline phosphatase is reduced. In the osteocytes of immature bone tissue bundles the reaction productis missing. The activity of acid phosphatase, likewise, is lower than after 14 days, but in comparison with alkaline phosphatase activity it is much higher. Restructuring of bone regenerate takes place with reminiscences of granules and PAW 1 and Bio-Oss Collagen membrane.

Within 60 days after surgery, the bone defect in the jaw is filled with bone structure, which completely replaces the fibrous tissue. It contains spongy bone, well-structured newly formed bone bundles, cavities with bone marrow, numerous remodeled osteoblasts and osteoclasts on the surface of bone bundles.

As the newly formed bone tissue matures, after 60 days the activity of acid phosphatase is much lower.

The study of the dynamics of the bone metabolism markers in animals blood highlighted the increase of bone thermolabile alkaline phosphatase after 30 days, the maximum being recorded after 60 days - $+20 \%(p<0.05)$ from the beginning of the experiment (table 1). Bone tartrate-resistant phosphatase activity, on the contrary, decreases veridically by $22 \%$ over 60 days after implantation, whereas at other research terms the changes of this enzyme proved to be statistically inconclusive. At the same time, there is a veridical increase in the ratio values between bone alkaline phosphatase and bone acid phosphatase 60 days after the implantation by $54 \%$ ( $p$ $<0.05$ ). The changes found denote the stimulation of the osteoregenerative processes in the mandibular tissue under the influence of the remedies used.

Over 30 days after the beginning of the experiment, under the influence of biomaterials PAW 1 matrix and Geistlich Bio-Oss Collagen, the level of average molecules (AM) increased by $35 \%(p<0.05)$, nucleotide substances (NS) by $35 \%$ ( $p<0.05$ ), as well as nitric oxide - by $29 \%$. The increase of AM, NS and nitric oxide in the blood serum of experimental animals under the influence of implanted biomaterials indicates their osteoregenerative and osteoconductive actions.

\section{Conclusions}

Analysis of the dynamics of bone metabolism markers in animals blood highlighted an increased activity of bone thermolabile alkaline phosphatase after 30 days, the maximum level being reached after 60 days - an increase by $20 \%(p<0.05)$ compared to the beginning of the experiment. Bone tartrate-resistant phosphatase activity, on the other hand, decreased veridically by $22 \%$ after 60 days.

Under the influence of implanted biomaterials PAW 1 matrix and Geistlich Bio-Oss Collagen, after 30 days the level of average molecules (AM) increased by $35 \%$ ( $p$ $<0.05)$, nucleotide substances (NS) - by $35 \%(p<0,05)$, as well as nitric oxide - by $51 \%(p<0.05)$. After 60 days, the values of these indices showed a decreasing tendency: at this research term AM exceeded the control values by $29 \%$, NS - by $13 \%$, and nitric oxide - by $29 \%$. The increased levels of these substances in animals blood indicate their osteoregenerative action.

Based on this experimental study, biomaterials PAW 1 and Bio-Oss have shown beneficial qualities, and their application contributes to active bone regeneration. The formation of new bone tissue occurs directly on the surface of biomaterials, which exhibits an osteoconductive action.

\section{References}

1.ADCOCK, J. E., Changing concepts in periodontics. // Texas dent. J., 1988, vol. 105, nr. 3, p. 6-12.

2.CAFFESSE, R. O., SMITH, B. A., NASYLETY, C. E., LOPATIN, D. E., Cell proliferation after flap surgery, root conditioning and fibronectin application. // J. Periodontol., 1987, vol. 58, nr. 10, p. 661-666.

3.CAFFESSE, P. O., KERRY, G. J., CHAVES, E. S. et al., Clinical evaluation of the use of citric acid autologous fibronection in periodontol surgery. // J. Periodontol. 1988, vol. 59, S9, p. 565-569.

4.CRISTENSON, R. H., Biochemical markers of bone metabolism: an overview. // Clin. Biochem, 1997, vol. 30 (nr. 8), p. 573-593.

5.CHETRUS V., Analize Stiintifice, ediia a X-a, vol 4, p.436, Chisinau 2009.

6.CHETRUS V., Dinamica proceselor osteoregenerative în tratamentul complex al parodontitelor marginale cronice.//Revista,Curierul Medical, Chisinau 2005.nr.2(284) p.30-32.

7.DELMAS, P. D., GARNERO, P., Biological markers of bone turnover in osteoporosis. // Stevenson J. C., Lindsay R., eds. Osteoporosis. London: Chapman and Hall Medical, 1998, p. 117-136.

8.DELMAS, P. D., EASTELL, R., GARNERO, P., et al., The use of biochemical markers of bone turnover in osteoporosis. // Osteoporosis Int., 2000, nr. 11 (suppl. 6), p. 2-17.

9.DUMITRIU, H. T., Parodontologie, Bucuresti, Editura Viata Medicala Romaneascã, 1997, $351 \mathrm{p}$.

10.MC GUIRE, M. K., Periodontal surgery. Resection, regeneration and reconstruction of osseous tissue. // Texas dent. J., 1988, vol. 105, nr. 11, p. 28-33.

11.PERIS, P., ALVAREZ, L., MONEGOL, A., GUANABENS, N., DURAN, M. et. al., Biochemical markers of bone. Turnover after surgical menopause and hormone replacement therapy. // Bone (USA), 1999, sep., 25(3), p. 349-353.

12.PONTORIERO, R., NYMAN, S., LINDHE, J., ROSENBERG, E., SANAVI, $F$., Guided tissue regeneration in treatment of furcation defects in man. // J. Clin. Periodontol., 1987, vol. 14, nr. 10, p. 618-620.

13.SEIBEL, M., WOITGE, H. M., Biochimical markers of bone metabolism. Update 1999. Part I: Basic principles. // Rev. Clin. Lab., 1999, vol. 45 , nr. 5-6, p. 237-25

$\overline{\text { Manuscript received: } 29.05 .2019}$ 